
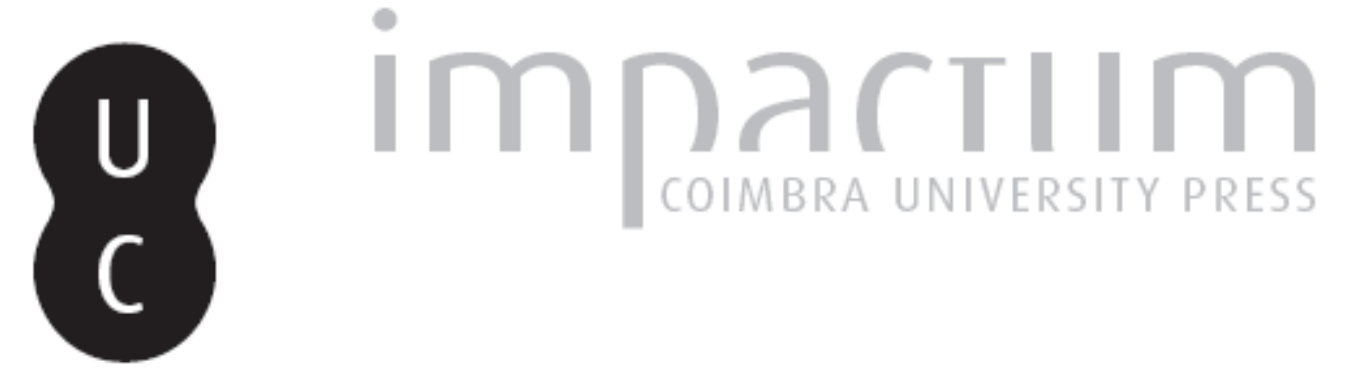

\title{
A procura da harmonia ou quem tem medo da arquitectura moderna?
}

\section{Autor(es): $\quad$ Costa, Alexandre Alves}

Publicado por: FCTUC. Serviço Editorial do Departamento de Arquitectura

URL persistente:

URI:http://hdl.handle.net/10316.2/37406

DOI:

DOI:http://dx.doi.org/10.14195/0874-6168_1_1

Accessed : $\quad$ 26-Apr-2023 06:52:35

A navegação consulta e descarregamento dos títulos inseridos nas Bibliotecas Digitais UC Digitalis, UC Pombalina e UC Impactum, pressupõem a aceitação plena e sem reservas dos Termos e Condições de Uso destas Bibliotecas Digitais, disponíveis em https://digitalis.uc.pt/pt-pt/termos.

Conforme exposto nos referidos Termos e Condições de Uso, o descarregamento de títulos de acesso restrito requer uma licença válida de autorização devendo o utilizador aceder ao(s) documento(s) a partir de um endereço de IP da instituição detentora da supramencionada licença.

Ao utilizador é apenas permitido o descarregamento para uso pessoal, pelo que o emprego do(s) título(s) descarregado(s) para outro fim, designadamente comercial, carece de autorização do respetivo autor ou editor da obra.

Na medida em que todas as obras da UC Digitalis se encontram protegidas pelo Código do Direito de Autor e Direitos Conexos e demais legislação aplicável, toda a cópia, parcial ou total, deste documento, nos casos em que é legalmente admitida, deverá conter ou fazer-se acompanhar por este aviso.

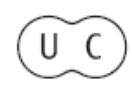




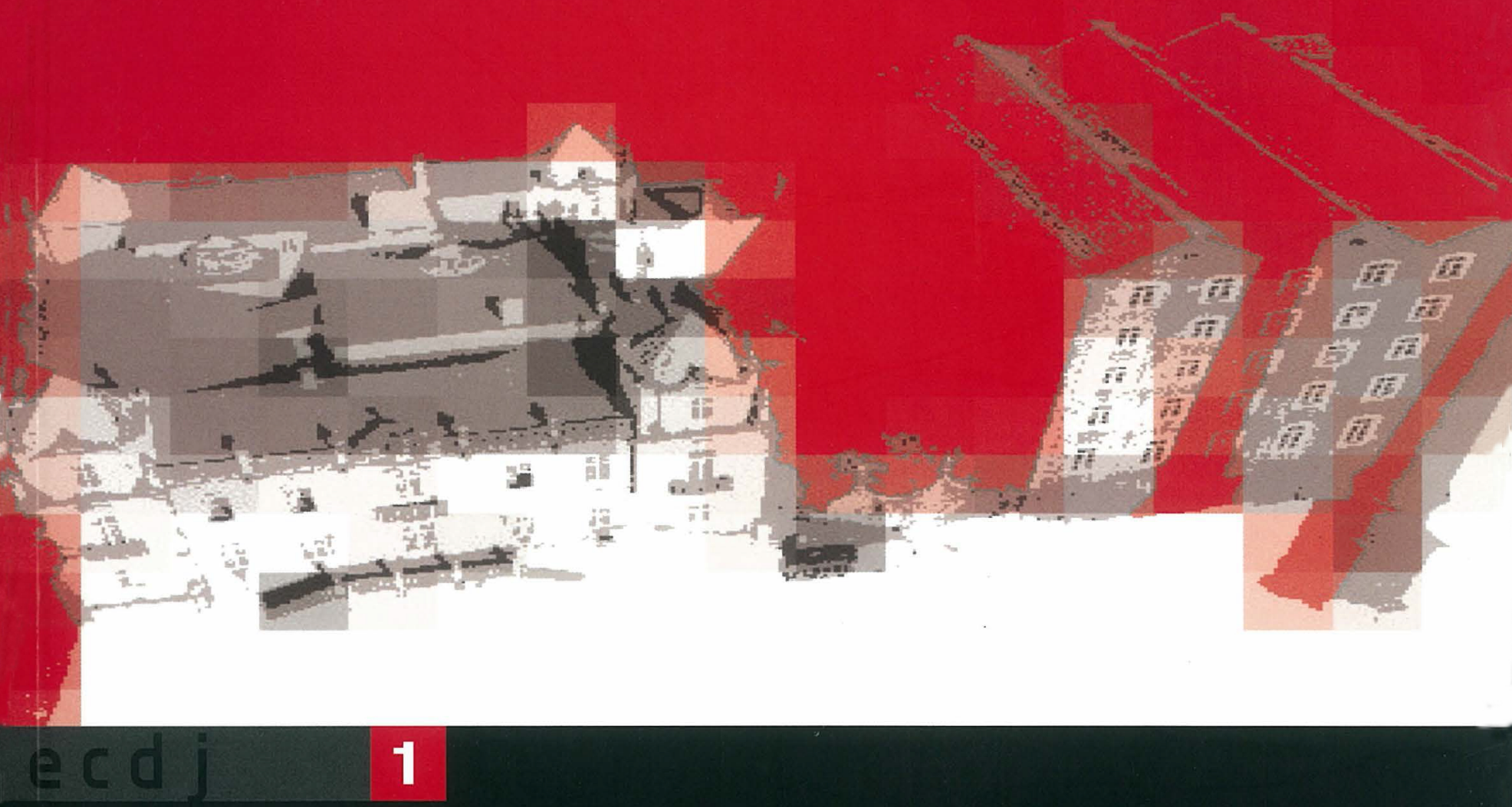

fctuc / departamento de arquitectura

\section{a polémica do Freixo Fernando Távora} alexandre alves costa | antónio olaio joão paulo rapagão | jorge figueira josé antónio bandeirinha

(2) 


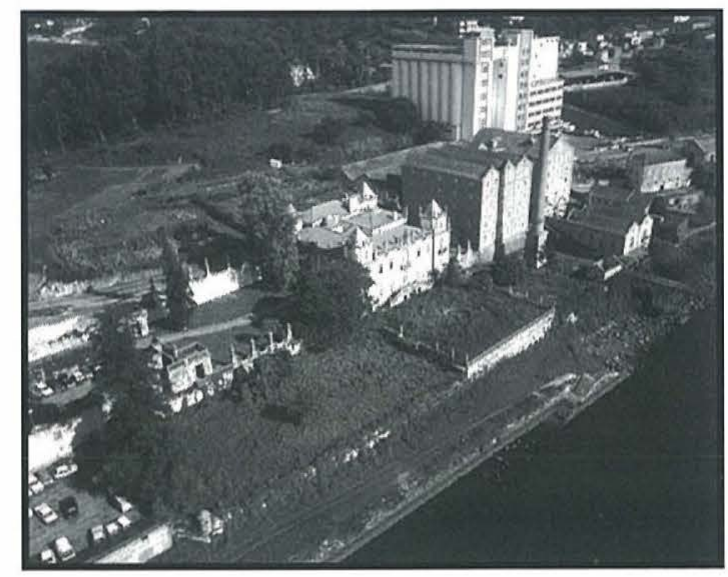


Tenho escrito sobre Fernando Távora alguns textos que reli. Reparo, agora, como transformar em discurso verbal, crítico e interpretativo, o que é visível e tão claro na sua obra, foi redundante e demasiado fácil. E, na impossibilidade de me remeter para o discurso hermético, abundante de referências extra-disciplinares, que hoje transformou a crítica de arquitectura numa actividade ensaística de super especialistas afastados do ofício, vejo que me coloquei sempre, em relação a Távora, numa posição mais próxima do biógrafo.

> Talvez, também, por respeito à sua figura tão próxima e familiar. Para outros a tarefa de o relerem com verdadeira distância crítica! > Em Távora se revê a Escola do Porto, pelo menos até agora. Com ele construímos os alargados consensos que nos tem permitido enfrentar os desequilibrios ou os novos equilíbrios da contemporaneidade.

A sua lição fundamental decorre simplesmente da sua capacidade única para distinguir o essencial do supérfluo ou circunstancial e, enquanto nos dividiamos pela circunstância, com ele nos uníamos no reforço e consideração dos valores mais perenes, cimentados pela presença permanente de uma moral que nunca admitiu qualquer atropelo na defesa da dignidade do Homem. Uma tal abstracção poderia ter aberto caminho a todas as perversidades se não estivesse, como no seu caso, activamente vigilante na construção da felicidade de todos os homens, respeitadas as sua diferenças e por elas olhados e amados no dia a dia da vida tão apaixonadamente vivida. $E$ foi neste aparente paradoxo da referência à essência e do apego à qualidade do momento que Távora construiu o seu magistério e a sua obra, como resultado natural da sua forma de estar no mundo.

> As suas lições marcaram profundamente o que tem sido chamado de "Escola do Porto" e que não é mais do que a rejeição constitutiva de qualquer "estilismo" cenográfico e anedótico a pretexto ou com o alibi da morte das visões totalitárias e da mobilidade e dispersão do mundo contemporâneo.

> A obra de Távora nunca abandonou a fidelidade afirmada ao Movimento Moderno. Mas, ao contrário de outros, talvez mais velhos e imaturos, transformou a fidelidade em coisa inclusiva e não exclusiva. Daí a sua continuidade e a sua coerência e, sobretudo, a sua permanente contemporaneidade. Mas o que marcou profundamente a Escola ao longo dos seus mais de quarenta anos de magistério, foi a compatibilização

\section{[a procura da harmonia ou quem tem medo da arquitectura moderna?]}

Alexandre ALVESCOSTA 
desta conviç̧ão moderna com a tentativa de elaboração de um método e não com a defesa e transmissão de um código formal, foi a consideração da História como um instrumento operativo para a construção do presente, foi, não só a consideração da Arquitectura na sua adequação construtiva e funcional, mas sobretudo como representação de cada um porque representa todos, fazendo de cada edifício um corpo vivo, um organismo com alma e imagem próprias.

> Nunca se tratou, na sua obra nem no seu pensamento, de revogar o Movimento Moderno. Tratou-se de manter uma ordem arquitectónica com valor universal que o integrasse e redefinisse permanentemente. Sem produzir novos modelos, cada obra é um percurso de reflexão que, do sítio, abarca toda a cidade e no sítio fixa a forma, cada forma. Para Távora, servir o real não é rejeitar as aportações inegáveis do racionalismo e a ascese real que ele significa para a arquitectura. É tomar uma posição corajosa de busca - inquietante no aceitar que cada tema tem o seu carácter, a sua problemática específica, a sua expressão própria. Ao arquitecto de hoje só "um critério de experiência" é lícito; um critério que não recuse dado algum do real que, esse sim, existe, nunca como matéria a sujeitar a soluções apriorísticas e abstractas.

> Quem decidiu entregar o projecto do Palácio do Freixo ao Arquitecto Fernando Távora por ter pensado ser ele a pessoa indicada para o restaurar, pela sua reconhecida cultura histórica e empenho no seu permanente reconhecimento, enganou-se profundamente. Basta conhecer a sua obra de reutilização de edifícios para se entender que Távora nunca obvia a sua condição de projectista na procura de uma coerência do desenho, sempre transformador, que, obrigatoriamente compatível com a releitura do fluir da história, manipula os elementos do real para o clarificar.

> Távora sabe bem que todos construímos sobre o construído, que não há pedaço de terra que não tenha sido humanizado. Sabe que esse é o nosso património, mesmo que fragmentado, desordenado ou obscurecido. Defendê-lo é para ele, sempre, considerá-lo vivo, moldável, transformável, matéria de projecto para a construção do futuro que o contenha e o acrescente.

> O projecto de reconversão do arruinado Convento de Santa Marinha da Costa tem um valor ímpar na história recente da arquitectura 
portuguesa por constituir, mais do que uma notável obra, a abertura precoce de um novo período na história e vivência do património.

> A Carta de Veneza, determinando que a intervenção nova se deve manter claramente diferente da antiga e, ajudando a esclarecê-la, deve mostrar-se e mostrá-la, levou a que muitos trabalhos de reutilização de edifícios, no seu afã de afirmação da nossa época, tantas vezes retórica, neutralizassem a preexistência, tomada como pano de fundo, lugar estabilizado e intocável. Esta posição respeitadora, embora, do passado que não lhe interessa interpretar, impõe a sua marca, estabilizando para sempre a vida do edifício ou do conjunto.

> Reaberto o debate sobre a intervenção nos edifícios ou conjuntos de interesse patrimonial que se segue à aceitação da rigidez normativa da Carta de Veneza, paralelamente à criação de um cada vez mais complexo corpo de jurisprudência e elaboração de planos de salvaguarda sobre a defesa e valorização dos bens patrimoniais, tende hoje a considerar-se que cada caso é um caso e que a teoria da intervenção nascerá de cada circunstância nunca generalizável circunstância de que fazem parte não só a expressão da individualidade de cada autor, como a obrigação ética de um rigoroso e exaustivo reconhecimento histórico e arqueológico do edifício a transformar. Do "silêncio", à intervenção activa e transformadora do próprio edifício ou conjunto, a novidade é a consideração da história como matéria de um projecto de autor.

> No panorama da melhor arquitectura que se pratica em Portugal podemos alinhar algumas opções distintas que permitem o alargamento do debate a partir do estudo de alguns casos.

> Na Pousada da Flor da Rosa, de Carrilho da Graça, o edifício antigo é o documento/monumento, respeitado, cuidadosamente restaurado e abandonado. A intervenção nova distingue-se e afasta-se física e morfologicamente. Tem uma lógica de composição a que nada importa a do anterior edifício respeitando sobretudo os valores de escala ou de ecdj $+1 \cdot 15$ textura que favorecem uma valorização recíproca, cada um a servir de cenário ao outro. Os poucos momentos de intercepção, sempre no espaço interior, referem a reversibilidade da "decoração" moderna. Trata-se de uma respeitável e sensível interpretação da Carta de Veneza. 
> No Convento do Bouro de Souto de Moura, o edifício preexistente é apropriado depois de fixado o seu carácter de ruína. É o espaço da ruína que é habitado. A construção é consolidada sem interpretação, nem reconhecimento do seu carácter. São apagados vestígios que possam perturbar a sua pacificação; o telhado não é reconstruído; as novas funções são alojadas com aparente pragmatismo sem necessidade de nova apropriação de espaços que tiveram funções idênticas no passado. $O$ usufruto da ruína é um prazer puramente estético, a intervenção apaga-se em absoluto minimalismo expressivo.

> O aparente romantismo da posição, humildemente passiva em relação à interpretação dos valores da história do edifício, esconde a transformação absoluta da construção em obra de autor, na sua totalidade.

> A Casa dos Bicos em Lisboa, de Manuel Vicente e Santa Rita, é, no polo oposto do Bouro, verdadeiramente romântica na sua vertente não ruinista mas de reposição historicista e revivalista à maneira dos finais de oitocentos. A consideração da história pelo lado da linguagem da decoração que se usa estilizada mas ostensivamente modernizada, em confronto com alterações estruturais de fundo. Uma Casa dos Bicos neo-manuelina para usos do século XX.

> A visita a todos estes edifícios é acompanhada de folhetos explicativos da sua história. E pode assim ser porque lhes puseram termo. A intervenção actual não faz parte da narrativa. Inicia e acaba outra.

> Assim se vai mantendo criticamente a Carta de Veneza ou se vai dela fazendo tábua rasa.

> Fernando Távora entra no Convento da Costa, futura Pousada de Santa Marinha em Guimarães, com uma postura próxima da simplicidade com que os nossos mestres pedreiros sempre encararam a continuação ou alteração das obras dos seus predecessores.

Assim o fizeram todos os mestres da Batalha ou dos Jerónimos, actualizando linguagens, sem alterações de conteúdo, assim o fizeram no Convento de Cristo de Tomar, alterando e sobrepondo linguagens correspondentes a novos conteúdos decorrentes de uma forte ideologização das intervenções.

> Távora trabalha e molda a preexistência, usa-a como matéria de projecto. Relê nela o fluir da história e, aceitando sobreposições ou aposições estilísticas ou de linguagem, usa de todos os meios para o 
clarificar. Não prescindindo da investigação histórica e arqueológica, anota fases de desenvolvimento, dando-lhes sem moralismo, uma nova dignidade. A intervenção actual é mais uma, desenhada com regras claras que resultam da interpretação da história, incluindo a contemporânea. A posição de Távora é tão activa e obrigatoriamente culta que pode actuar, também, restaurando, corrigindo, repondo ou, ao contrário, demolindo qualquer elemento espúrio que provoque opacidade na leitura clara da essência do projecto global, entendido como um processo colectivo de longa duração.

> O que fica dito e é depois concretizado em posteriores projectos, do Mosteiro de Refóios ao Anfiteatro de Direito da Universidade de Coimbra e ao projecto para o denominado conjunto do Palácio do Freixo, é que, usando o real, que contém o seu passado e o futuro desejado, Távora encontra a regra a partir do existente, caso a caso e sempre legível em cada obra.

Estética e ética, ambas início e fim de um percurso, sempre inclusivo, de reflexão e desenho, fazem Távora atravessar o século como consciência permanente de que a analogia do belo com o bom não é a analogia do absoluto, mas a analogia da necessidade do limite(1). A sua lei moral impede-o de deixar espaço ao demasiado belo, aceitando, sem nenhum dramatismo, o caminho da heterodoxia para atingir a utilidade da arquitectura.

> Por outras palavras. Távora não é um restaurador e nunca actua a favor de uma época ou de um estilo contra outros. A valoração hegemónica é a do seu projecto ordenador, para que a ordem, que é a sua aspiração, inclua todas as épocas, sem moralismos nem a-prioris estilísticos. Távora não quer habitar o caos, como se de esplendor se tratasse, quer habitar o próprio esplendor. A sua construção é, neste caso, facilitada por se centrar inevitavelmente numa obra prima da arquitectura portuguesa - o Palácio do Freixo, de Nasoni.

É, também, contra ela dirigida a ofensa de não permitir o cumprimento ecdj $ə \vdash \cdot 17$ do seu projecto.

> Se acrescentarmos a tudo isto as perspectivas para o futuro próximo da cidade, anunciadas através da exposição de projectos da Câmara Municipal do Porto, torna-se claro que aquela perda é coerente com a adopção desses projectos e o que lhes é comum. 